\title{
Article Review and Case Report of Cutaneous Rosai-Dorfman Disease with Pinna Involvement
}

\author{
Pineda Cásarez F , German Navarro Anaya2*, Díaz Sainz D E², Díaz Reyna D², Gómez De la Cruz C A², Ruiz \\ Gudiño $C^{2}$, Torres Carreón A G ${ }^{2}$ and Falcón García JM ${ }^{2}$ \\ ${ }^{1}$ Department of Otolaryngology and Head and Neck, Regional Hospital "General Ignacio Zaragoza" ISSSTE, Mexico \\ ${ }^{2}$ Resident of LaSalle University, Department of Otolaryngology and Head and Neck, Regional Hospital "General Ignacio Zaragoza" ISSSTE, Mexico
}

Submission: October 18, 2017; Published: October 30, 2017

*Corresponding author: German Navarro Anaya, Resident of LaSalle University, Department of Otolaryngology and Head and Neck, Regional Hospital “General Ignacio Zaragoza” ISSSTE, Mexico City, Mexico, Email: germannavarroanaya@hotmail.com

\begin{abstract}
Rosai-Dorfman disease, also known as sinus histiocytosis with massive lymphadenopathy, is considered a benign affection of unknown cause. However, it is thought that alterations in the immune system may cause the disease. It was described in 1969 by Rosai and Dorfman; ever since, about 600 cases of cutaneous affection have been reported around the world. In Mexico, there have been only eighteen cases. The extranodal affections occur in the $43 \%$, including: skin, nasal cavity, paranasal sinus, the orbits, bones, and the central nervous system. A histological study is important for diagnosis, where a histiocyte and plasma cell infiltration shows histiocytes positive for S100 and CD68 protein. This is the case report of an eleven year old male allergic to penicillin, gentamicin, and clindamycin, with no other relevant clinical history.

The patient was referred to the emergency department due to massive bilateral pinna growth, as well as non-painful erythematous nodular lesions. The patient added that he went for a swim a week before showing any symptom. The diagnosis: pinna perichondritis. Antibiotics and non-steroidal anti-inflammatories were prescribed, though the lesions did not improve. In a requested immunological profile, BHC, acute phase reactants were reported normal. A biopsy showed an inflammatory reaction throughout the dermis and the perichondrium, excluding the ear cartilage. The pathology outcome shows: moderate chronic perichondritis, histological and morphological changes that match the cutaneous Rosai-Dorfman disease. The immune-histochemical studies performed with S-100 positive CD-1a negative, confirm diagnosis. Apart from the eighteen cases reported in Mexico since 1969, only one has been reported with cutaneous bilateral pinna affection.
\end{abstract}

\section{Hearing before birth}

Rosai-Dorfman disease is a type of histiocytosis described by pathologists Juan Rosai and Ronald Dorfman in 1969. The disease is a benign lymphoproliferative disorder of unknown cause, which usually affects the cervical ganglia. It is accompanied by other extranodal manifestations in $43 \%$, that, most of the time, manifest as cutaneous alterations (16\%). The extranodal manifestations might also affect some other organs, such as: the central nervous system, kidneys, glands, the digestive system and bones. Though of unknown etiology, the disease is believed to originate from an alteration of the immune system. Due to its benign course, it is a self-limiting entity; few are the permanent cases. Macroscopically, the cutaneous lesions are characterized by papules, nodules, plaques, lesions in the form of tumor, erythematous lesions. Microscopically, it is characterized by polymorphic, plasmacytic infiltrate interspersed with histiocytes, some frothy. The diagnosis is made by a histopathological report, along with the results of the immunohistochemistry positive to protein S-100. The clinical presentation of this case is of relevance to a proper diagnosis for it could be wrongly interpreted as an infectious ear perichondritis. In Mexico, eighteen cases have been reported since 1969. Only one case has been reported with cutaneous presentation involving bilateral pinna.

\section{Methodology}

Table 1: Authors and reported cases in Mexico since 1969.

\begin{tabular}{|c|c|}
\hline Alvarado-Cabrero y cols & 1 \\
\hline Molina-Carrion LE et al & 1 \\
\hline Flores-Carrillo VM et al & 1 \\
\hline Arrecillas-Zamora y col & 1 \\
\hline Ortiz Hidalgo C y col & 4 \\
\hline Navarrete FG y col & 9 \\
\hline Quezada PE & 1 \\
\hline
\end{tabular}




\section{Global Journal of Otolaryngology}

After a systematized review of Mexican literature looking for case reports of Rosai-Dorfman disease, we found a total amount of 7 published articles including a total of 18 patients (Table 1). Among all of these cases, only one presents cutaneous RosaiDorfman bilateral pinna affection. The following search engines were consulted: pubmed, clinical key, Cochrane, www.scielo.org. $\mathrm{mx} /$ scielo.php, medigraphic.com, www.imbiomed.com.mx, http:// biblat.unam.mx/es.

\section{Case}

Eleven year old male allergic to penicillin, gentamicin, and clindamycin, with no other relevant clinical history. Disease basic manifestations include: bilateral pinna with rapid increase in volume, presenting non-painful erythematous papulo-nodular lesions, without other symptoms such as fever, general discomfort, otorrhea. He reported that he had gone for a swim the previous week; thus, we suspected pinna perichondritis of infectious etiology. The exploration showed both erythematous pinna with increased volume, with papulo-nodular lesions in cocha, helix and anti-helix of different sizes that did not exceed $1 \mathrm{~cm}$. (Figure 1). There was no pain to manipulation and exploration. Integral, slightly erythematous, tympanic membranes are observed. No alterations or lesions were found at the level of the nostrils, oral cavity, facial region and oropharynx. Neck did not present cervical lymphadenopathy. There was no evidence of other injuries at that time.

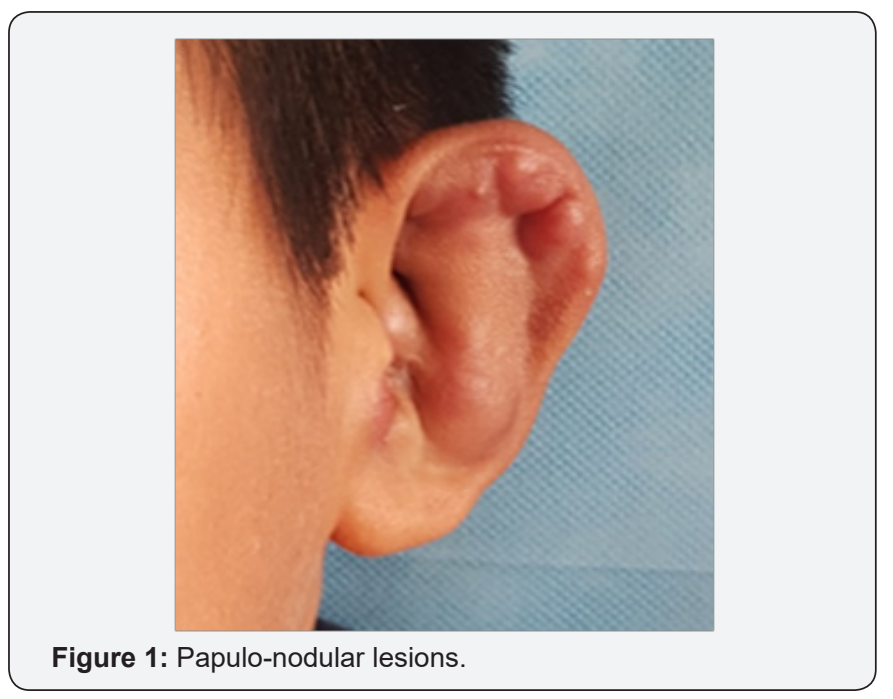

Antibiotics and analgesics were prescribed with no clinical improvement, and showing no changes in the lesions. A prednisone regimen (1mg / kg / day) was given for 10 days without any improvement during the appointments hence, the requested immunological tests and other paraclinics (Table 2). Afterwards, it was decided to undergo an incisional biopsy of the right pinna lesion. The pathology report showed perichondrial tissue with intense chronic swelling, and skin with moderate inflammation with presence of leukocyte infiltrate interspersed with histiocytes, some frothy. It was subsequently sent to immunohistochemistry with S100 positive and CD1a negative results, confirming Rosai-
Dorfman cutaneous disease. The diagnosis was sent to different specialties for integral assessment in order to rule out alterations or lesions in other areas (Figure 2).

Table 2: Paraclinicals.

\begin{tabular}{|c|c|}
\hline WBC & 7.54 \\
\hline NEU\# & $58 \%$ \\
\hline LYM\# & $31.3 \%$ \\
\hline MON\# & $5.3 \%$ \\
\hline EO\# & $2.1 \%$ \\
\hline HGB & 14.9 \\
\hline HCT & $41.9 \%$ \\
\hline MCV & 84.7 \\
\hline $\mathrm{MCH}$ & 30.2 \\
\hline PLT & 273 \\
\hline GSR & 40 \\
\hline C3 & $155 \mathrm{mg} / \mathrm{dl}$ \\
\hline $\mathrm{C} 4$ & $20.3 \mathrm{mg} / \mathrm{dl}$ \\
\hline ANTI RO & 0.2 \\
\hline ANTI LA & 2.7 \\
\hline C-RP & 2.6 \\
\hline $\mathrm{RF}$ & 11.5 \\
\hline IGG & $1450 \mathrm{mg} / \mathrm{dl}$ \\
\hline IGM & $102 \mathrm{mg} / \mathrm{dl}$ \\
\hline IGA & $354 \mathrm{mg} / \mathrm{dl}$ \\
\hline IGE & $17.1 \mathrm{mg} / \mathrm{dl}$ \\
\hline $\mathrm{AF}$ & 152 \\
\hline BT & 0.52 \\
\hline PT & 7.7 \\
\hline ALT & 78 \\
\hline AST & 64 \\
\hline FIBRINOGEN & $393 \mathrm{mg} / \mathrm{dl}$ \\
\hline $\mathrm{PT}$ & 11.2 \\
\hline APTT & 25.6 \\
\hline TT & 19.7 \\
\hline $\mathrm{CC}$ & $86 \mathrm{ml} / \mathrm{min}$ \\
\hline
\end{tabular}

\section{After biopsy}

\begin{tabular}{|l|} 
Figure 2: After biopsy. \\
Fiops.
\end{tabular}




\section{Global Journal of Otolaryngology}

Study protocol for histiocyte disease was performed with complete blood count, liver function tests, urinalysis, and clotting times, showed regular levels, except for the high ESR (Table 2). Imaging tests included thorax x-ray and chest lateral, skull lateral $\mathrm{x}$-ray, computed tomography of the neck and thorax, magnetic resonance of the brain, and aspiration of bone marrow. There was no further evidence of alterations in results. Currently, the patient remains asymptomatic, with periods of remission and activation of the lesions affecting only pinna (Figure 2). Once we ruled out injuries in other levels, we chose an expectant management and close monitoring (Figure 3).

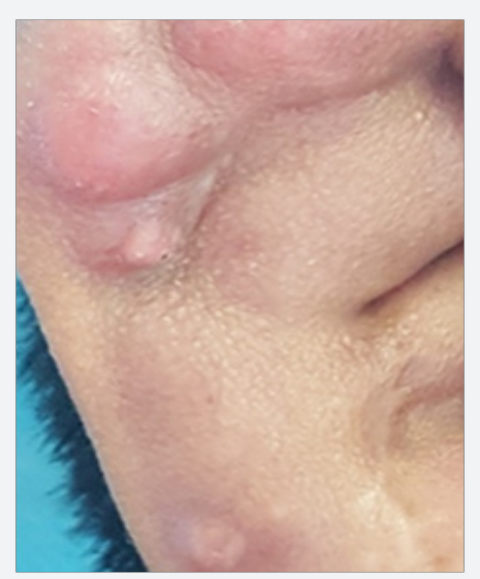

Figure 3: Papulo-nodular lesions with pustular acneiform lesions.

\section{Discussion}

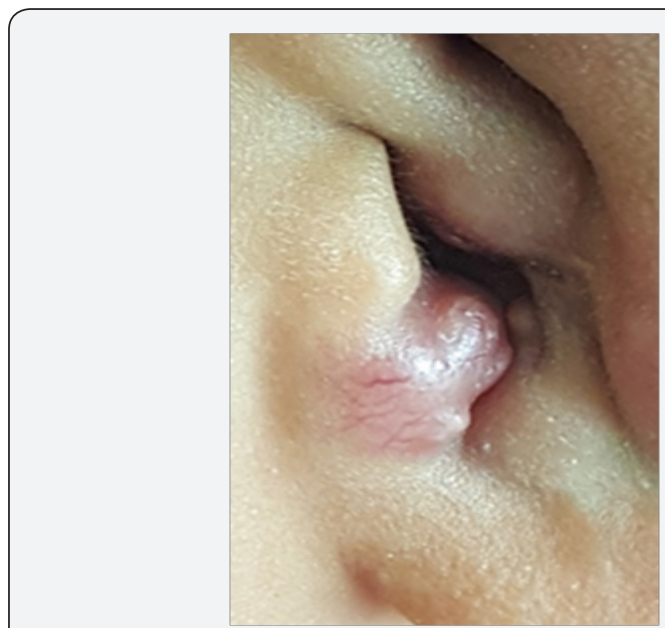

Figure 4: Pustular acneiform on EAC lesion.

Rosai-Dorfman disease, also known as Sinusal Histiocytosis with Massive Cervical Lymphadenopathy (SHML), is a rare entity with little etiology and treatment known. The extranodal variety with cutaneous component is even less common. The first cases of this disease were documented by Destombes in 1965, but it was until 1969 when Rosai and Dorfman acknowledged the disease as a pathological clinical one [1] (Figure 4). The term cutaneous Rosai Dorfman disease is used exclusively for variants of the disease where the condition is restricted to the skin, which speaks of a local condition. Due to the variation of the disease, it is of great importance to distinguish and study the patient to determine whether or not it is a systemic condition, for it might be accompanied by a skin alteration at the same time. This will also depend on the treatment. The extranodal form occurs in a $43 \%$; and the skin is up to a $16 \%$ most frequently affected [2-4].

\section{Epidemiology}

Rosai Dorfman disease may manifest at any age group but it is more common among children and young adults. The disease is rather common among men than among women. It has been proven that the extranodal manifestation in its cutaneous variant is more frequent in 50 year old adults. Affected patients have no record of cutaneous disease. Besides, they do not show cervical lindaphenopathy, and their laboratory results show no particular alteration. Pure cutaneous Rosai-Dorfman disease is quite unusual, reporting only 578 cases since 1969. From which only $11.2 \%$ have affected the cervicofacial region [5]. In an article recently reported by Taiseer Hassan Hassan Al-Khateeb, they reviewed in the literature that, of the 578 cases of skin disease, 4 cases affected the pinna [5]. In Mexico, 18 cases have been reported, and only 2 (including the patient of this report) have affected the pinna. The etiology is still unknown. Hypothetically, the disease is induced by an immune disorder triggered by a reaction to a viral infection. However, any proves remain unclear so far. Some agents -such as herpesvirus 6, or Epstein-Barr- might be considered as key elements to elicit the disease.

\section{Clinical Manifestations}

The most frequent feature of Rosai-Dorfman disease shows bilateral, painful cervical lymphadenopathy with fever, night sweats and weight loss. Lymph nodes may be affected at the mediastinal, inguinal, and retroperitoneal levels. The most affected sites are the skin, the upper aerodigestive route, bones, eyes and retro-orbital tissue. The affections can manifest in isolation as well as at the onset of the disease. Other cases have been reported with affection to CNS, digestive system, urogenital system, glands, liver, pancreas and lungs. At the head and neck level the condition is seen in $22 \%$ of cases, most commonly the nasal cavity. This entity can simulate many malignant lymphoproliferative diseases. Also, depending on the site of injury, it can simulate other diseases and mislead the diagnosis. For instance, at the central nervous system the disease behaves radiologically as a meningioma, but very suggestive data on Rosai-Dorfman disease can be determined, such is the case of emperipolesis at the cerebrospinal fluid [6].

The benign course disease is defined by a spontaneous and permanent remission within a considerable amount of the cases. Nevertheless, clinically, five evolutionary patterns have been described:

a) complete and spontaneous remission ( $50 \%$ of cases);

b) chronic course with exacerbations and remissions; 
c) persistent and stable disease (with permanence up to 19 years);

d) progressive disease; and,

e) lymph node and extraganglionic dissemination with fatal evolution ( $7 \%$ of cases). Some authors have reported cases without lymph node involvement and non-lymph node involvement, characterizing them only as Rosai-Dorfman disease and not sinusoidal histiocytosis with massive lymphadenopathy [7]. There is an exceptional case reported in the literature where a Langerhans Histiocytosis and RosaiDorfman disease coexisted in the same patient [4-11].

Rosai-Dorfman Cutaneous Disease is a non-systemic entity confined to the skin without cervical lymphadenopathy, and with distinct epidemiological characteristics. It mainly affects adults during the 5th decade of life [12-15]. The lesions are characterized by papules, indurated erythematous nodules, pustular acneiform lesions, and psoriasiform lesions. It is of a benign course and of spontaneous remission. Lesions might be $1 \mathrm{~cm}$ up to $10 \mathrm{~cm}$ long $[15,16]$ within the different classifications of histiocyte and dendritic cell diseases, there are the following:

\section{A. World Health Organization (WHO): histiocytosis classification}

\section{i. Class I:}

a) Langerhans cell histiocytosis (LCH).

b) Histiocytosis of mononuclear phagocytes other than Langerhans cells.

ii. Class II:

a) Familial and reactive haemophagocytic lymphohistiocytosis (HLH).

b) Sinus histiocytosis with massive lymphadenopathy (SHML or Rosai-Dorfman disease).

c) Juvenile xanthogranuloma (JXG).

d) Reticulohistiocytoma.

iii. Class III:

a) Malignant histiocytic disorders.

b) Acute monocytic leukaemia (FAB M5).

c) Malignant histiocytosis.

d) True histiocytic lymphoma.

B. Histiocyte Society: histiocytosis classification.

Disorders of varying biological behaviour:

a) Dendritic cell-related.

b) LCH.

c) Juvenile xanthogranuloma and related disorders including Erdheim-Chester disease, and solitary histiocytomas with juvenile xanthogranuloma phenotype.

d) Secondary dendritic cell disorders.

i. Monocyte/macrophage-related:

a) Haemophagocytic lymphohistiocytosis (familial and sporadic).

b) Secondary haemophagocytic syndromes (infection, malignancy, or autoimmune-associated, or other).

c) SHML.

d) Solitary histiocytoma of macrophage phenotype.

ii. Malignant disorders:

a) Dendritic cell-related

I. Histiocytic sarcoma (localised or disseminated)

b) Monocyte/macrophage-related

I. Leukemias (monocytic leukemias M5A and B, acute myelomonocytic leukemia M4, chronic myelomonocytic leukemia).

II. Extramedullary monocytic tumours or sarcoma (monocytic counterpart of granulocytic sarcoma).

III. Macrophage-related histiocytic sarcoma (localised or disseminated)

iii. Histiocyte Society: clinical classification of LCH

a) Single-system:

i. $\quad$ One organ system involved.

ii. Usually bone, skin, lymph nodes, lungs, or the thyroid or pituitary gland.

b) Multi-system:

i. 2 or more organ systems involved.

ii. Can be with or without involvement of risk organs.

c) Risk organs:

i. Specific organs are considered high-risk because the associated mortality rates in those who do not respond to treatment are high.

ii. High-risk organs include the liver, spleen, lung, and bone marrow.

iv. Laboratory studies: Laboratory studies are not specific. We can find leukocytosis and elevation of the rate of globular sedimentation (ESR). Elevation of gamma globulins can be found. Some patients have other haematological alterations, such as autoimmune hemolytic anemia. In cases of hematological alterations such as anemia, leucopenia or thrombocytopenia, bone marrow aspiration is recommended. 
A follow-up to laboratory studies is suggested to be performed every 6 months.

v. Image: Bone lesions are typical, thus, they may bear a resemblance to Langerhans histiocytosis. They are useful when requesting lateral of skull, Panoramic x-ray of jaws, lateral and tele of thorax, in order to identify osteolytic lesion. Neck and Chest CT is helpful to determine the presence of lesions in other organs or masses that are not palpable. Magnetic resonance imaging is of great help in analyzing soft tissue; it is also useful to determine the extent of the disease in other organs. PETscan with $18 \mathrm{~F}$ fluorodeoxyglucose (FDG) is an effective tool for determining post-treatment injury activity. Since it is important to detect alterations at the CNS level, it is necessary to perform imaging studies such as skull CT or MRI of the brain to analyze the pituitary gland.

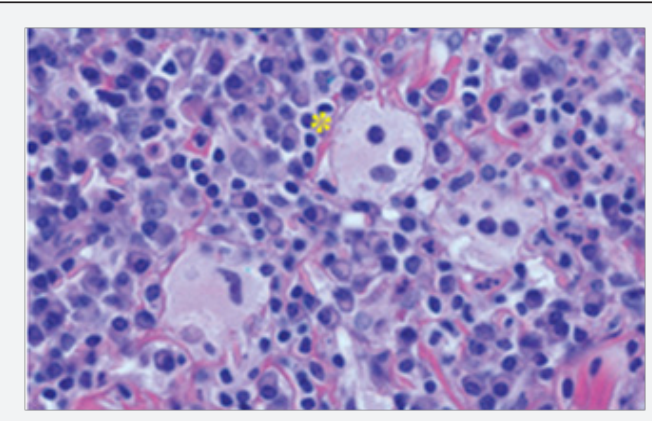

Figure 5: Histiocytes with phagocytic lymphocytes (emperiopolesis).

vi. Diagnosis: Given that diagnosis is histopathological, a biopsy is always necessary. This entity often resembles other benign or malignant lymphoproliferative disorders. The main difference between Langerhans Histiocytosis and RosaiDorfman disease is the immunohistochemistry, where we report positivity to the $\mathrm{S} 100$ protein and negativity to the CD1a protein, since in Langerhans histiocytosis the latter is positive (Figure 5).

The histological features are lymph nodes with pericapsular fibrosis and sinus dilation, hence the name of Sinusal Histiocytosis with Massive Cervical Lymphadenopathy. A massive infiltration of histiocytes, lymphocytes, and plasma cells will be found. The main characteristic is that there is a presence of emperiopolesis, which means that these histiocytes will contain other lymphocytes inside (Figure 5). These histiocytes express not only S100, but they are also positive for CD68, CD163, alpha-anti-chymotrypsin, alphaantitrypsin and CD1a is typically negative.

The differential diagnosis will depend on the site of injury since it might be misleading and usually diagnosed when the decision to biopsy is made. Regarding our case, at the beginning, it led us to suspect a pinna pericondritis of infectious etiology because it was present in an acute way. Showing no response to treatment, and because of the clinical characteristics (such as the presence of bilateral lesions), we found out that it was another entity. In a report published by Molina-Carrión LE et al, they explain a case of neurological manifestations with intracranial injury, which turned out to be deceptive. It was thought to be an intracranial tumor -in that case, meningioma- also compromising the spinal cord. The surgical treatment was carried out as probable meningioma until the biopsy report indicated Rosai-Dorfman disease [13].

vii. Treatment: The treatment will depend on the extent of the disease and the organs involved. Usually due to its benign course no handling is necessary. When vital structures are compromised, it is decided to start a treatment to avoid complications. [17] Surgery is only for biopsy purposes. On the other hand, when structures such as the airway or central nervous system are involved, injuries must be removed. If a complete resection of the lesion generates excessive morbidity, partial resections can be performed. Subsequent adjuvant therapy can be initiated with radiotherapy. Cortico-steroids have no long-term utility since they will not modify lesions in more than $91 \%$ of patients [5].

A particular case showed lesions decrement and symptom improvement with a prolonged course of low-dose steroids with prednisone with airway obstruction [17]. Therapy with antimetabolites, such as methotrexate (MTX) and 6-mercaptopurine, has been used with little success $20 \%$. Imatinib therapy with inhibitor tyrosine kinase with a dose of 400-600mg daily for 7 months, has been successful in some cases. [18] The use of monoclonal antibodies such as Rituximab has also been reported [19]. Expectant treatment and monitoring are recommended in those cases with no compromised vital structures. The duration of treatment with low doses of prednisone has not been defined in patients with massive cervical lymphadenopathy. Surgery is recommended for patients with vital organ compression; there is an $80 \%$ success rate for such cases. Radiotherapy will be necessary in cases resistant to treatment. Further research is also necessary to determine the benefits with monoclonal antibodies such as Rituximab or Imatinib, which is a tyrosine kinase inhibitor.

\section{Conclusion}

In our case, we chose an expectant management and monitoring, in case of skin presentation only. The patient was diagnosed a year and five months ago. He has been presenting remission and intermittent activation of the lesions only at the auricle. Other areas have not been compromised and remain asymptomatic. The reason why this particular area is affected is still unknown. This patient will require long term follow-up.

\section{References}

1. Albertz A, Nicolas, Godoy S, Jose Miguel, Cabezas L, et al. (2011) Causa poco común de obstrucción nasosinusal recurrente: Enfermedad de Rosai-Dorfman. Rev Otorrinolaringol Cir Cabeza Cuello 71(2): 155160.

2. Pinto, Daniele Cristine Gomes (2008) Rosai-Dorfman disease in the differential diagnosis of cervical lymphadenopathy. Rev. Bras. Otorrinolaringol 74(4): 632-635. 
3. Frater JL, Maddox JS, Obadiah JM, Hurley MY (2006) Cutaneous RosaiDorfman Disease: Comprehensive Review of Cases Reported in the Medical Literature since 1990 and Presentation of an Illustrative Case. J Cutan Med Surg 10(6): 281-290.

4. Quezada PE, Escobar GG, Castrejón VMI, Gorraez MMT, Guido BR, et al. (2008) Enfermedad de Rosai-Dorfman (histiocitosis sinusoidal con linfadenopatía masiva): comunicación de un caso y revisión de la bibliografía. Revista Alergia México 55(5): 206-211.

5. Al Khateeb Taiseer Hussain Hassan (2016) Cutaneous Rosai-Dorfman Disease of the Face: A Comprehensive Literature Review and Case Report. Journal of Oral and Maxillofacial Surgery 74(3):528-540.

6. Navarrete FG, Novales J (2001) Histiocitosis sinusal cutánea. Estudio clínico patológico. Dermatología Rev Mex 45(4): 173-179.

7. Ortiz Hidalgo C, Cuesta Mejia TC, Ochoa Ochoa C, Valen zuela Espinosa A y col (2003) Enfermedad de Rosai-Dorfman, limitada a la piel Informe de 4 casos. Gac Med Mex 139(1): 1-6.

8. Ferrer R y col (2003) Enfermedad de Rosai-Dorfman (histiocitosis sinusal con linfadenopatía masiva): a propósito de un caso. Acta Otorrinol Angl Esp 54: 384-387.

9. Rosai J, Dorfman F (1969) Sinus histicyitosis with massive lymphadenopathy. A newly recognized benign clinic pathological entity. Arch Pathol 87: 63-70.

10. Rosai, J, Dorfman RF (1972) Sinus histiocytosis with massive lymphadenopathy: A pseudolymphomatous benign disorder. Analysis of 34 cases. Cancer 30: 1174-1188.

11. Arrecillas-Zamora, OrtizHidalgo C, Uribe-Uribe N, Chávez-Macías
L, Olvera-Rabiela JE (2011) Histiocitosis de células de Langerhans con enfermedad de Rosai Dorfman. Informe de un caso de autopsia. Patología Rev Latinoam 49(1):S26-S30.

12. Flores-Carrillo VM (2014) Enfermedad de Rosai-Dorfman en glándula suprarrenal. Informe de un caso clínico. Rev Med Inst Mex Seguro Soc 52(2): 224-227.

13. Molina-Carrión LE (2014) Enfermedad de Rosai-Dorfman. Reporte de un caso clínico. Rev Med Inst Mex Seguro Soc 52(2):218-223.

14. Alvarado-Cabrero y cols (2006) Enfermedad de Rosai-Dorfman en glándula mamaria. Informe de un caso y revisión de la literatura. Gac Méd Méx 146: 3.

15. Cole S, Finlay J (1999) 2-Chlorodeoxyadenosine for adults with multisystem Langerhans cell histiocytosis. Med Pediatr Oncol 33: 512.

16. Pulsoni A, Anghel G, Falcucci P (2002) Treatment of sinus histiocytosis with massive lymphadenopathy (Rosai-Dorfman disease): report of a case and literature review. Am J Hematol 69(1): 67-71.

17. Horneff G, Jurgens H, Hort W (1996) Sinus histiocytosis with massive lymphadenopathy (Rosai-Dorfman disease): response to methotrexate and mercaptopurine. Med Pediatr Oncol 27(3): 187-192.

18. Utikal J, Ugurel S, Kurzen H (2007) Imatinib as a Treatment Option for Systemic Non-Langerhans Cell Histiocytoses. Arch Dermatol 143(6): 736-740.

19. Petschner F, Walker UA, Schmitt-Graff A (2001) "Catastrophic systemic lupus erythematous" with Rosai-Dorfman sinus histiocytosis. Successful treatment with anti-CD20/rituximab. Dtsch Med Wochenschr 126(37): 998-1001.

\section{Your next submission with Juniper Publishers will reach you the below assets}

- Quality Editorial service

- Swift Peer Review

- Reprints availability

- E-prints Service

- Manuscript Podcast for convenient understanding

- Global attainment for your research

- Manuscript accessibility in different formats ( Pdf, E-pub, Full Text, Audio)

- Unceasing customer service

Track the below URL for one-step submission https://juniperpublishers.com/online-submission.php 